\title{
PERSPECTIVAS ACTUALES DEL TURISMO GASTRONÓMICO SEGÚN LAS APORTACIONES DEL CONGRESO INTERNACIONAL CIENTÍFICO- PROFESIONAL DE TURISMO CULTURAL (CÓRDOBA, ESPAÑA)
}

\author{
Cinthia Rolim de Albuquerque Meneguel \\ Doctora en Turismo y Hostelería \\ Instituto Federal de Educação, Ciência e Tecnologia de São Paulo - Câmpus Cubatão \\ cameneguel@gmail.com \\ Manuel Rivera Mateos \\ Doctor en Geografía \\ Universidad de Córdoba \\ manuel.rivera@uco.es
}

\section{Resumen}

Objetivo: Identificar la producción científica sobre turismo gastronómico en el Congreso Internacional Científico-Profesional de Turismo Cultural (2015-2019) con el objeto de caracterizar y extraer las aportaciones más relevantes sobre la situación actual y las perspectivas de desarrollo en este campo de investigación.

Metodología: Estudio exhaustivo de la programación de comunicaciones (550 trabajos), de entre los cuales un total de 50 comunicaciones se refieren al turismo gastronómico. Partiendo de una metodología de investigación cualitativa, exploratoria y descriptiva, se realiza un análisis de los contenidos y sus diversos enfoques y variables de estudio.

Originalidad/Relevancia: No se había realizado ningún estudio de caracterización de las aportaciones de este Congreso, por lo que carecía de una visión de conjunto y perspectiva general sobre la investigación reciente a nivel internacional sobre las distintas modalidades del turismo cultural en este evento. El análisis de esta temática congresual, nos ha permitido conocer el comportamiento y los enfoques de análisis de los investigadores a la hora de consolidar conocimiento científico sobre la materia.

Principales resultados: La diversidad de perspectivas, contenidos y herramientas metodológicas sobre el turismo gastronómico nos indican no sólo que estamos ante un fenómeno ciertamente complejo, sino también de importantes potencialidades para la mejora de la oferta y atractivos de destinos turísticos.

Contribuciones teóricas/metodológicas/gestión: Ha contribuido finalmente a ampliar los horizontes y puntos de mira del turismo gastronómico en el ámbito académico-científico, teórico-conceptual y el técnico-profesional, mostrando las tendencias más recientes e innovadoras y los productos turístico-gastronómicos más emergentes y de mayores potencialidades de desarrollo futuro.

Palabras-clave: Estudios turísticos. Contribuciones científicas. Turismo gastronómico.

\section{Cite como}

American Psychological Association (APA)

Meneguel, C. R. A., \& Mateos, M. R. (2021, set./dez.). Perspectivas actuales del turismo gastronómico según las aportaciones del congreso internacional científico-profesional de turismo cultural (Córdoba, España). PODIUM Sport, Leisure and Tourism Review, São Paulo, 10(3), 114-139. https://doi.org/10.5585/podium.v10i3.17717. 
Meneguel, C. R. A., \& Mateos, M. R. (2021, set./dez.). Perspectivas actuales del turismo gastronómico según las aportaciones del congreso internacional científico-profesional de turismo cultural (Córdoba, España)

\title{
PERSPECTIVAS ATUAIS DO TURISMO GASTRONÔMICO DE ACORDO COM AS CONTRIBUIÇÕES DO CONGRESSO CIENTÍFICO-PROFISSIONAL INTERNACIONAL DO TURISMO CULTURAL (CÓRDOBA, ESPANHA)
}

\section{Resumo}

Objetivo: Identificar a produção acadêmica sobre turismo gastronômico no Congresso Internacional Científico-Profissional de Turismo Cultural (2015-2019), a fim de caracterizar e extrair as contribuições mais relevantes e as perspectivas atuais existentes neste campo de estudo do turismo.

Metodologia: Estudo abrangente da programação de comunicações (550 trabalhos), dentre os quais 50 comunicações no total se referem ao turismo gastronômico. Partindo de uma metodologia de investigação qualitativa, exploratória e descritiva, procede-se à análise do conteúdo e de suas várias abordagens e variáveis de estudo.

Originalidade/Relevância: Não foi realizado nenhum estudo de caracterização das contribuições deste Congresso Internacional, faltando, portanto, uma visão e perspectiva geral das pesquisas internacionais recentes sobre as diferentes modalidades do turismo cultural tratado neste evento. Análise do tema deste Congresso permitiu conhecer o comportamento e as abordagens de análise dos investigadores no que diz respeito à consolidação do conhecimento científico sobre a temática.

Principais resultados: A diversidade de perspectivas, conteúdos e abordagens sobre o turismo gastronômico indica que não apenas estamos enfrentando um fenômeno complexo, mas também de importante potencial para melhorar a oferta e as atrações de destinos turísticos.

Contribuições teóricas/metodológicas: Contribuiu para ampliar os horizontes e pontos de vista sobre o turismo gastronômico em âmbito acadêmico-científico, teórico-conceitual e técnico-profissional ou prático, evidenciando as tendências recentes e inovadoras e os produtos turísticos-gastronômicos emergentes e com maior potencial de desenvolvimento futuro.

Palavras-chave: Estudos turísticos. Contribuições científicas. Turismo gastronômico.

\section{CURRENT PERSPECTIVES OF GASTRONOMIC TOURISM ACCORDING TO THE CONTRIBUTIONS OF THE INTERNATIONAL SCIENTIFIC-PROFESSIONAL CONGRESS OF CULTURAL TOURISM (CÓRDOBA, SPAIN)}

\begin{abstract}
Objective: Identify the scientific production about gastronomy tourism in the International ScientificProfessional Congress on Cultural Tourism (2015-2019) in order to characterize and extract the most relevant contributions and the current perspectives in this field of research.

Methodology: Exhaustive study of the communication programming (550 papers), of which 50 communications refer to gastronomy tourism. Starting from a qualitative, exploratory and descriptive research methodology, an analysis of the contents and its various approaches and study variables is carried out.

Originality: Until now, no characterization study had been carried out on the contributions of this Congress, so it lacked an overview and general perspective on recent international research at the international level on the different modalities of cultural tourism in this event. The analysis of this Congress theme has allowed us to know the behavior and analysis approaches of researchers when it comes to consolidating scientific knowledge on the subject.

Main results: The diversity of perspectives, contents and methodological tools on gastronomy tourism indicate not only that we are facing a certainly complex phenomenon, but also of significant potential for improving the offer and attractions of tourist destinations.

Theoretical/methodological contributions: It has finally contributed to broadening the horizons and points of view of gastronomy tourism in the academic-scientific, theoretical-conceptual and technical-professional fields, showing the most recent and innovative trends and tourism-gastronomy products more emerging and with greater potential for future development.
\end{abstract}

Keywords: Tourism studies. Scientific contributions. Gastronomic tourism. 
Meneguel, C. R. A., \& Mateos, M. R. (2021, set./dez.). Perspectivas actuales del turismo gastronómico según las aportaciones del congreso internacional científico-profesional de turismo cultural (Córdoba, España)

\section{Introducción}

El turismo es una de las actividades económicas más dinámicas y en continua transformación, de manera que en los últimos años ha experimentado una importante extensificación geográfica y diversificación en tipologías, formas, productos y contenidos para adaptarse a una demanda cada vez más diversa amplia (Donaire, 2012; Russo \& Richards, 2016). A partir de la década de los ochenta del siglo pasado la demanda de turismo cultural se desarrolló de manera exponencial (Rojek \& Urry, 1997), paralelamente a la mayor concienciación y sensibilización sobre las potencialidades de valorización de los bienes culturares, tanto materiales como inmateriales, a la vez que fue diversificándose también y generando productos, servicios y visiones nuevas que fueron más allá del patrimonio monumental (Appadurai, 2001).

El turismo cultural se ha convertido en un nicho de mercado especializado capaz de involucrar y movilizar a un gran número de turistas interesados por aspectos tan variados como los aspectos históricos, artísticos, científicos, monumentales, paisajísticos o patrimoniales en sentido amplio, tanto en zonas urbanas como rurales (Selby, 2004; Richards, 2007; Russo \& Richards, 2016). El patrimonio cultural material e inmaterial cumple, por lo demás, un papel fundamental en las sociedades actuales, debido a los valores que fomenta: identitarios, educativos, económicos, culturales y sociales (Benhamou, 2016).

Pues bien, entre las múltiples manifestaciones del turismo, el patrimonio culinario y gastronómico ha alcanzado una especial significación para no pocos destinos turísticos (Kivela \& Crotts, 2006; Everett, 2012). De hecho, han proliferado en las dos últimas décadas los estudios, desde perspectivas multidisciplinares diversas, sobre la alimentación y la gastronomía en el ámbito del turismo, siendo al fin y al cabo dos fenómenos complejos pero de notable actualidad y trascendencia socioeconómica y cultural, tal como se viene comprobando por el interés despertado de esta temática en los medios de comunicación tanto generalistas como especializados.

Actualmente, la gastronomía es un componente importante del turismo cultural, por cuanto permite al turista acercarse más directamente a las señas de identidad cultural de los destinos visitados al tiempo que vivir una experiencia sensorial y también cultural más satisfactoria. Así, la gastronomía para muchos turistas no es sólo y meramente una necesidad básica humana, sino parte central de la experiencia turística (Richards, 2002; Hall, \& Sharples, 2008; Henderson, 2009; Horng, \& Tsai, 2010), bien sea durante su estancia, en la que busca 
Meneguel, C. R. A., \& Mateos, M. R. (2021, set./dez.). Perspectivas actuales del turismo gastronómico según las aportaciones del congreso internacional científico-profesional de turismo cultural (Córdoba, España)

generalmente algo especial, sensorial y diferencial, o incluso después de regresar a su destino de origen, en el que puede llegar a cocinar e intentar recrear los platos y recetas gastronómicas degustadas en el destino visitado, compartiéndolas con amigos y familiares.

El patrimonio culinario local contribuye a reforzar y diferenciar la imagen de los destinos turísticos (Chang, Kivela, \& Mak, 2010; Ellis, Park, Kim, \& Yeoman, 2018), además de ampliar y enriquecer la oferta turística (Chen, \& Huang, 2017), atraer a una demanda específica principalmente motivada por la degustación y disfrute de los productos y platos regionales y la búsqueda de experiencias culturales asociadas y de carácter auténtico (Okumus, Okumus, \& McKercher, 2007), de manera que la gastronomía se cada vez más un factor determinante del nivel de satisfacción de los turistas en sus estancias en cualquier destino (Smith, \& Costello, 2009; Choe, \& Kim, 2018).

El turismo gastronómico proporciona, asimismo, todo un estímulo a toda la cadena productiva y de valor de la gastronomía (Hwang, Kim, Choe, \& Chung, 2018), ya que genera de manera directa o indirecta numerosas y variadas actividades tales como visitas a productores de agroalimentarios, restaurantes y establecimientos de comidas, festivales gastronómicos, rutas temáticas especializadas y visitas a lugares e instalaciones relacionados con los atributos más característicos de la cultura culinaria local (Hall, \& Sharples, 2003; Smith, \& Costello, 2009; Chang, \& Yuan, 2011; Everett, 2012). Por tanto, el patrimonio gastronómico y sus manifestaciones asociadas se han convertido ya en un recurso territorial y un producto turístico derivado ciertamente fundamental, estratégico y competitivo para el sector turístico (Horng, \& Tsai, 2010).

Y, en nuestro caso, de la importancia de la gastronomía en los destinos de turismo cultural, da buena cuenta el Congreso Internacional Científico-Profesional de Turismo Cultural, que viene desarrollándose desde 2015 ininterrumpidamente todos los años en la ciudad de Córdoba (España), ciudad con varias declaraciones como "Patrimonio de la Humanidad" de la UNESCO: la Mezquita-Catedral en 1984, su Centro Histórico en 1994, la festividad y cultura inmaterial de los Patios de la ciudad en 2012 como Patrimonio Inmaterial de la Humanidad, y el yacimiento arqueológico de Medina Azahara - Ciudad Califal en 2018. Además su zona geográfica de localización se integra en la región de la Dieta Mediterránea, reconocida también en 2013 por la UNESCO como Patrimonio Inmaterial de la Humanidad, y el Flamenco en 2010.

El Congreso Internacional Científico-Profesional de Turismo Cultural tiene como finalidad promover el debate y diálogo sobre el perfil de la demanda turística y la evolución y la innovación de la oferta ante las necesidades y nuevos desafíos derivados de los cambios 
Meneguel, C. R. A., \& Mateos, M. R. (2021, set./dez.). Perspectivas actuales del turismo gastronómico según las aportaciones del congreso internacional científico-profesional de turismo cultural (Córdoba, España)

acaecidos en las sociedades del siglo XXI y la búsqueda perentoria de la sostenibilidad sociocultural en la actividad turística. Las discusiones y estudios de caso del Congreso desarrollados por un importante elenco de académicos y profesionales pretenden servir para compartir experiencias e ideas sobre esta temática, además de promover o fortalecer la cooperación e intercambio científico a través de redes de investigación nacionales e internacionales (Congreso Internacional Científico-Profesional de Turismo Cultural, 2020).

Por otra parte, los eventos académicos-científicos como el que aquí estudiamos se han desarrollado notablemente en los últimos años, con importantes efectos y resultados como instrumentos notables de gran impacto mediático, socioeconómico y a nivel de intercambio, comunicación y trasferencia de conocimientos, lecciones aprendidas y buenas prácticas (Gónzalez-Quijano, 1995; Meadows, 2000; Butler, \& Visser, 2006; Jeong, \& Kim, 2010). En definitiva, están adquiriendo un papel cada vez más relevante a medida que la transmisión de nuevas ideas y hechos llega al conocimiento de la comunidad científica con mayor rapidez (Martens, \& Saretzki, 1993) y estás fortalecen los niveles de implicación, participación, intercambio y cooperación científico-técnica en el marco de un escenario turístico cada vez más cambiante y competitivo.

El análisis de los anales del congreso y su apuesta por los enfoques multitemáticos e interdisciplinares en el estudio de las diversas subtipologías y tendencias del turismo cultural en general y gastronómico en particular, nos ha permitido conseguir resultados satisfactorios y multifacéticos que no podrían haberse obtenido en el ámbito de publicaciones o eventos de temática más restringida o específica y tanto sobre aspectos teóricos como sobre estudios de casos (Martens, \& Saretzki, 1993; Lisée, Larivière, \& Archambault, 2008). Dicho esto, el presente trabajo tiene como objetivo principal identificar la producción académica y científica sobre turismo gastronómico en el Congreso Internacional Científico-Profesional de Turismo Cultural. Y a partir de aquí comprender y caracterizar las aportaciones más relevantes y algunas de las novedades existentes en este campo de estudio del turismo. Hasta ahora no se había realizado ningún estudio bibliométrico y de caracterización de las aportaciones de este Congreso Internacional, por lo que se carece de una visión de conjunto y de una perspectiva general sobre la investigación reciente a nivel internacional sobre las distintas modalidades del turismo cultural tratadas en este evento científico-técnico. 
Meneguel, C. R. A., \& Mateos, M. R. (2021, set./dez.). Perspectivas actuales del turismo gastronómico según las aportaciones del congreso internacional científico-profesional de turismo cultural (Córdoba, España)

\section{Estructura organizativa, sesiones temáticas y métrica de comunicaciones del Congreso}

La organización del Congreso se estructura de una manera mixta con la participación no sólo de representantes y autoridades universitarias, sino también -por el mismo carácter científico-profesional que adquiere- con la intervención de representantes de Administraciones Públicas con competencias en turismo y de asociaciones empresariales y profesionales representativas del sector turístico invitadas expresamente como el Ministro de Industria, Energía y Turismo del Gobierno de España, la Secretaría de Estado de Turismo, la Consejería de Cultura, Turismo y Deporte de la Junta de Andalucía, entidades locales y Diputación Provincial de Córdoba y algunas autoridades de entidades públicas de turismo de varios países (Congreso Internacional Científico-Profesional de Turismo Cultural, 2020).

La colaboración con el sector público a través de la organización y los comités del Congreso persigue la consecución de acciones efectivas en materias de políticas públicas y planificación consensuadas con el sector privado y la transferencia de conocimiento aplicado de cara a promover el desarrollo sostenible del subsector del turismo cultural y la asistencia técnico-profesional a las iniciativas empresariales.

Aunque inicialmente este Congreso ha sido organizado a iniciativa de las Universidades Loyola Andalucía y de Córdoba (España), actualmente dicha organización forma parte del Comité Interuniversitario que ha dado pie a una amplia cooperación entre diversas redes de investigadores nacionales e internacionales e instituciones universitarias españolas e iberoamericanas como la Universidad Nacional de Costa Rica (Costa Rica), Universidad Nacional de la Patagonia Austral (Argentina), Universidad de Barcelona (España), Universitat Oberta de Cataluña (España), Escuela de Turismo y Hospitalidad de Ostelea (España), Universidad de Guadalajara (México) y Universidad de Michoacana San Nicolás de Hidalgo (México). En esta misma línea el propio Comité Científico está compuesto, de hecho, por miembros expertos de numerosas universidades españolas y extranjeras, iberoamericanas y europeas (Argentina, Bolivia, Colombia, Costa Rica, Cuba, Ecuador, México, Nicaragua, Portugal, República Checa, República Eslovaca, Túnez y Venezuela).

Durante sus distintas ediciones el Congreso se ha centrado en algún tema central que sirviera de eje orientador de los contenidos y objetivos principales para la discusión y debate sobre las diversas modalidades del turismo cultural (Tabla 1). 
Meneguel, C. R. A., \& Mateos, M. R. (2021, set./dez.). Perspectivas actuales del turismo gastronómico según las aportaciones del congreso internacional científico-profesional de turismo cultural (Córdoba, España)

\section{Tabla 1}

Temas centrales de las ediciones del Congreso Internacional Científico-Profesional de Turismo Cultural (2015-2019)

\begin{tabular}{|c|c|l|}
\hline EDICIÓN & AÑO & \multicolumn{1}{|c|}{ TEMA } \\
\hline I & $\mathbf{2 0 1 5}$ & $\begin{array}{l}\text { El papel que el Turismo Cultural puede aportar al crecimiento económico de las } \\
\text { regiones o ciudades donde se desarrolla. }\end{array}$ \\
\hline II & $\mathbf{2 0 1 6}$ & $\begin{array}{l}\text { El papel de las civilizaciones, el turismo emergente y de países lejanos, y cómo } \\
\text { las tipologías de Turismo Cultural pueden aportar al crecimiento de las regiones } \\
\text { o ciudades donde se desarrolla. }\end{array}$ \\
\hline III & $\mathbf{2 0 1 7}$ & $\begin{array}{l}\text { La gestión turística de sitios Patrimonio Mundial de la UNESCO, así como del } \\
\text { turismo gastronómico, dado que entre las necesidades y satisfacciones humanas } \\
\text { está la alimentación, germen del turismo gastronómico. }\end{array}$ \\
\hline IV & $\mathbf{2 0 1 8}$ & $\begin{array}{l}\text { Turismo patrimonial material e inmaterial y su sostenibilidad como elemento } \\
\text { dinamizador de las economías locales. }\end{array}$ \\
\hline V & $\mathbf{2 0 1 9}$ & $\begin{array}{l}\text { El patrimonio material e inmaterial como riqueza que conservar y valorizar a } \\
\text { través del Turismo Cultural Sostenible. }\end{array}$ \\
\hline
\end{tabular}

Fuente: Autores (2020).

Para profundizar y enmarcar los temas centrales propuestos en cada edición, el Congreso ha organizado todos los años una conferencia marco de apertura de sesiones con la participación de expertos invitados (Tabla 2). Tales conferencias han servido como marco catalizador de exposición de novedades y tendencias sobre la oferta, la demanda, el conocimiento y la gestión pública del turismo cultural a nivel nacional e internacional.

\section{Tabla 2}

Conferenciantes invitados en las ediciones del Congreso Internacional Científico-Profesional de Turismo Cultural (2015-2019)

\begin{tabular}{|c|c|l|}
\hline EDICIÓN & AÑO & INVITADO \\
\hline I & $\mathbf{2 0 1 5}$ & No está incluido en el programa publicado en el sitio web del congreso \\
\hline \multirow{2}{*}{ II } & $\mathbf{2 0 1 6}$ & Dr. Jordi Tresseras, Universidad de Barcelona - España \\
\cline { 3 - 3 } & $\mathbf{2 0 1 7}$ & Sr. Eusebio Leal, Historiador de la ciudad de la Habana - Cuba \\
\hline \multirow{2}{*}{ III } & \multirow{2}{*}{ IV } & Sr. Carlos Hiriart Pardo, Vicepresidente de ICOMOS - México \\
\cline { 3 - 3 } & \multirow{2}{*}{$\mathbf{2 0 1 9}$} & $\begin{array}{l}\text { Dña. Claudia Chavés López, Secretaria de Turismo del Estado de Michoacan } \\
\text { - México }\end{array}$ \\
\hline V & Sra. Secretaria de Estado de Turismo del Gobierno de España. \\
\hline
\end{tabular}

Fuente: Autores (2020). 
Meneguel, C. R. A., \& Mateos, M. R. (2021, set./dez.). Perspectivas actuales del turismo gastronómico según las aportaciones del congreso internacional científico-profesional de turismo cultural (Córdoba, España)

Las sesiones temáticas, por su parte, se subdividieron inicialmente en distintos subsegmentos de demanda y subtipologías de ofertas de turismo cultural, tales como turismo arquitectónico, turismo gastronómico, turismo de eventos culturales, turismo religioso, turismo industrial, turismo de compras, turismo idiomático, turismo gastronómico, turismo de flamenco, turismo de congresos y gestión del turismo cultural, sobre todo. A partir de su tercera edición, no obstante, se han ido incorporando otros grupos temáticos más diversos que recogen mayores niveles de especialización y segmentación de los estudios sobre el tema, tales como la gestión turística del Patrimonio Cultural Inmaterial de la UNESCO, las políticas de turismo cultural en el espacio cultural iberoamericano, el diseño e implementación de rutas e itinerarios culturales, el marketing turístico, las Tics y el comercio on line en el turismo cultural, la gestión de empresas turísticas culturales, la legislación turística aplicada con incidencia en esta tipología turística y la economía del turismo cultural. Esto ha permitido reforzar el carácter multi e interdisciplinar de los contenidos y objetivos del Congreso y ampliar de manera estimable sus perspectivas y enfoques para alcanzar una visión mucho más integral de la tipología del turismo cultural, incluyendo, además, sus relaciones y sinergias con otras tipologías y formas de turismo como el rural y de naturaleza, el ecoturismo, el turismo de sol y playa y el turismo genérico de interior, hasta el punto de que estas cuestiones están siendo abordadas en mesas y paneles temáticos específicos.

En el conjunto de sus distintas ediciones hasta 2019, se han presentado 550 comunicaciones y ponencias (Gráfico 1), con un promedio de 110 comunicaciones por año, siendo más numerosas en las anualidades de 2017 y 2018. En cualquier caso, es destacable el extraordinario crecimiento en número de aportaciones presentadas del congreso. 
Meneguel, C. R. A., \& Mateos, M. R. (2021, set./dez.). Perspectivas actuales del turismo gastronómico según las aportaciones del congreso internacional científico-profesional de turismo cultural (Córdoba, España)

\section{Gráfico 1}

Numero de comunicaciones en el Congreso Internacional Científico-Profesional de Turismo Cultural (2015-2019)

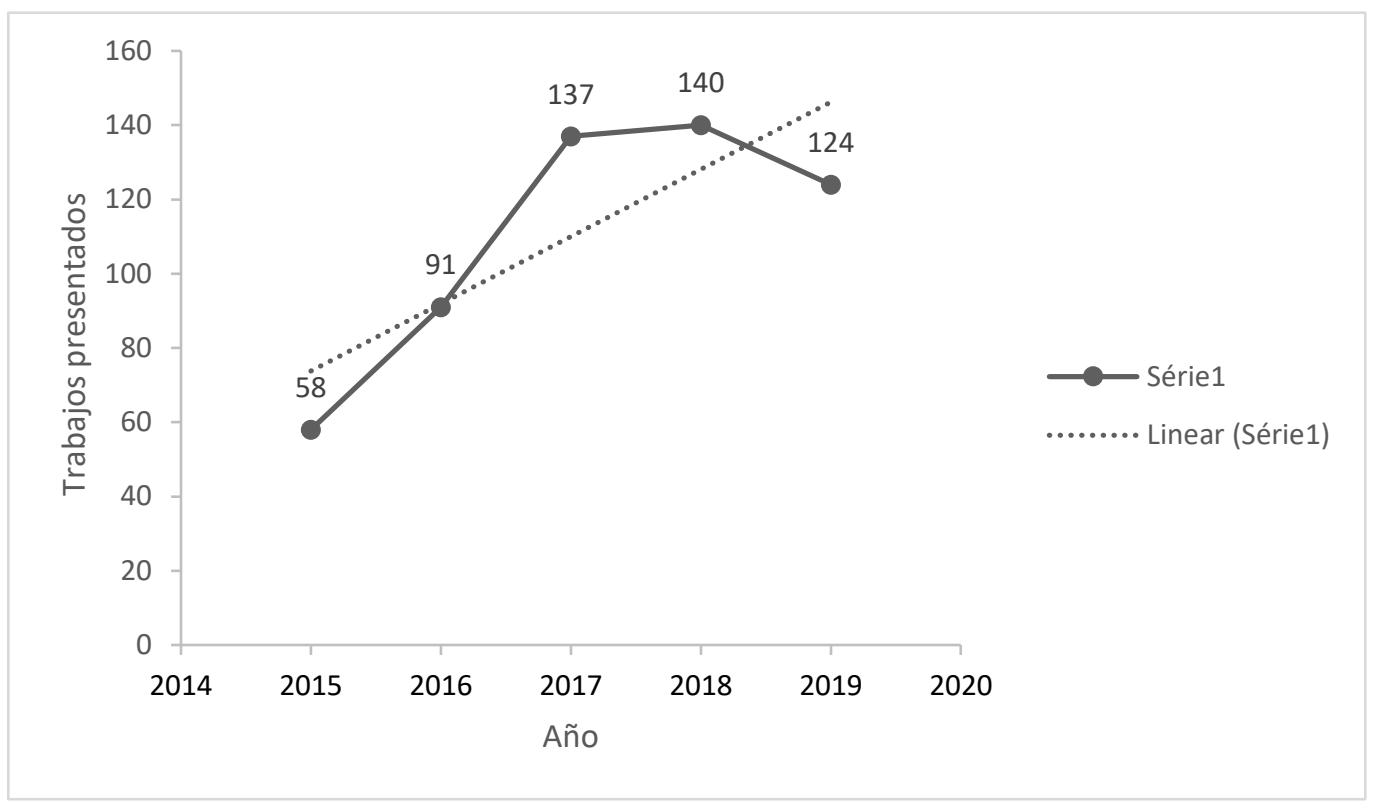

Fuente: Autores (2020).

En este estudio exploratorio hemos percibido la necesidad, para futuras ediciones del Congreso, de llevar a cabo un monitoreo y evaluación de las aportaciones finales mediante la realización de una encuesta de valoración de los participantes, asistentes y congresistas y a partir de aquí poder realizar un estudio métrico y un análisis cualitativo y cuantitativo más detallado para concretar los índices de relevancia y significación en materia de avances de conocimiento, innovación y transferencia de conocimiento alcanzados.

\section{Metodología}

El crecimiento de las publicaciones sobre turismo como campo de estudio ha sido ciertamente vertiginoso en las últimas décadas y entre sus principales tipologías y subsectores de análisis figura precisamente el turismo gastronómico y culinario en formatos de edición muy diversos (libros, artículos, actas de congresos, publicaciones académicas y docentes, etc.) (Yoo, \& Weber, 2005), si bien los anales y actas de congresos, seminarios científicos, jornada profesionales y otros eventos de carácter científico y/o técnico-profesional con los instrumentos clave para profundizar en la investigación sobre temáticas de turismo concretas. 
Meneguel, C. R. A., \& Mateos, M. R. (2021, set./dez.). Perspectivas actuales del turismo gastronómico según las aportaciones del congreso internacional científico-profesional de turismo cultural (Córdoba, España)

El presente trabajo se basa en un análisis esencialmente exploratorio y descriptivo para caracterizar e identificar las aportaciones y comunicaciones presentadas en el Congreso Internacional Científico-Profesional de Turismo Cultural de Córdoba (España) y relacionadas con la temática del turismo gastronómico, en el período de los primeros cinco años de realización de este Congreso (2015-2019). La metodología de análisis exploratorio-descriptivo es, en este sentido, bastante útil para proporcionar conocimiento derivado del tratamiento de este tipo de fuentes bibliográficas y documentales, tal como se podido constatar en numerosos estudios (Bernard, 1994).

Para la obtención de resultados y conclusiones, hemos exhaustivamente la programación de comunicaciones y ponencias en las diferentes mesas y paneles temáticos en la web oficial del Congreso, además de las publicaciones a las que han dado lugar, principalmente en la revista International Journal of Scientific Management and Tourism, que gestiona la asociación Investur, Grupo de Investigación SEJ-611 del Plan Andaluz de Investigación e Innovación (PAIDI).

La revisión sistemática de las aportaciones presentadas se ha realizado desde una perspectiva sintética e integradora en un proceso de tres fases fundamentales: 1.) establecimiento de los criterios de inclusión y aceptación de los trabajos; 2.) identificación y selección final de los trabajos de mayor interés y calidad; 3.) clasificación de los trabajos seleccionados por temáticas y subtipologías turísticas y contenidos más o menos relacionados con el turismo gastronómico (Hauser, Tellis, \& Griffin, 2006). Finalmente, el estudio exhaustivo de la programación de comunicaciones del congreso ha abarcado un total de 550 trabajos y aportaciones en los primeros cinco primeros años de organización de este evento congresual, lo que da buena cuenta de la importancia del mismo como fuente de conocimiento del turismo cultural en todas sus facetas, variantes y perspectivas de análisis. Entre estos trabajos, finalmente hemos identificado un total de 50 comunicaciones y ponencias que de manera central o en buena parte de sus contenidos se refieren al turismo gastronómico (aproximadamente un $10 \%$ del total de los trabajos presentados en el quinquenio estudiado).

Después de la recogida primaria de datos, hemos realizado un análisis cuantitativo y una primera interpretación de los mismos mediante software MS Excel, al tiempo que se ha realizado un análisis sistemático cualitativo de los contenidos, atendiendo variables y a la información descriptiva de los contenidos obtenidos en esta investigación, como suele ser normal y recurrente en este tipo de análisis (Silverman, 2005). En este sentido, las variables tenidas en cuenta han sido las siguientes: cantidad y autoría-filiación institucional de las 
Meneguel, C. R. A., \& Mateos, M. R. (2021, set./dez.). Perspectivas actuales del turismo gastronómico según las aportaciones del congreso internacional científico-profesional de turismo cultural (Córdoba, España)

comunicaciones, temas y enfoques tratados, clasificación científica en mesas temáticas, idioma, número de contribuciones por autores, palabras clave y conocimientos y experiencias intercambiados entre grupos o redes de investigación. Finalmente, la organización y estructuración de los resultados se ha realizado mediante el levantamiento de gráficos, tablas y figuras que pueden guiar al lector a la asimilación e interpretación de los datos presentados a lo largo de los contenidos del artículo (Martins, \& Theóphilo, 2009).

\section{Resultados y discusión}

Se han identificado, como hemos señalado anteriormente, un total de 50 trabajos con contenidos relacionados con el turismo gastronómico, cuyos títulos y autores se han indicado en la Tabla 3 siguiente.

Tabla 3

Título de las comunicaciones y sus autores en el Congreso Internacional Científico-Profesional de Turismo Cultural (2015-2019)

\begin{tabular}{|c|c|c|c|}
\hline EDICIÓN & AÑO & TITULO DE LA COMUNICACIÓN & AUTORES \\
\hline \multirow{11}{*}{ I } & \multirow{11}{*}{2015} & \multirow{2}{*}{$\begin{array}{l}\text { Património Gastronómico e sua valorização pelas } \\
\text { entidades público-privadas. O caso da Doçaria da } \\
\text { região do Algarve }\end{array}$} & Silvia Domingos \\
\hline & & & Cláudia Henriques \\
\hline & & \multirow{2}{*}{$\begin{array}{l}\text { Derechos de usuarios y deberes de las empresas de } \\
\text { restauración a la luz de la legislación turística y de } \\
\text { defensa del consumidor en Andalucía }\end{array}$} & Humberto Gosálbez Pequeño \\
\hline & & & José Manuel Serrano Cañas \\
\hline & & Turismo enológico: una experiencia para los sentidos & Beatriz Rodriguez Díaz \\
\hline & & $\begin{array}{l}\text { ¿Merecen ser turísticos todas las empresas y } \\
\text { establecimientos de restauración en Andalucía? A } \\
\text { propósito del concepto de servicio turístico de } \\
\text { restauración y clases de establecimientos en la } \\
\text { legislación turística de Andalucía }\end{array}$ & Humberto Gosálbez Pequeño \\
\hline & & $\begin{array}{l}\text { Las rutas del piscos como elementos turísticos } \\
\text { representativos de la cultura peruana }\end{array}$ & Ignacio Sariego López \\
\hline & & \multirow{3}{*}{$\begin{array}{l}\text { El turismo enológico en las Denominaciones de } \\
\text { Origen de Málaga: Revisión de la literatura }\end{array}$} & Francisca Vázquez Palmero \\
\hline & & & Genoveva Millán \\
\hline & & & Juan Manuel Arjona \\
\hline & & $\begin{array}{l}\text { El turismo y cultura en denominaciones de origen } \\
\text { enogastronómicas: El caso de la región Tokaj- } \\
\text { hegyalja (Hungría) }\end{array}$ & F. Xavier Medina \\
\hline \multirow{5}{*}{ II } & \multirow{5}{*}{2016} & \multirow{3}{*}{$\begin{array}{l}\text { Oleoturismo en la sierra de gata y las Hurdes } \\
\text { (Cáceres): análisis de su potencial a través de un test } \\
\text { de producto }\end{array}$} & José M. Hernández Mogollón \\
\hline & & & José A. Folgado Fernández \\
\hline & & & Ana María Campón Cerro \\
\hline & & \multirow{2}{*}{$\begin{array}{l}\text { Enoturismo en un destino del sol y playa. el caso de } \\
\text { la bodega las Tirajanas de Gran Canaria - España }\end{array}$} & Pedro Ernesto Moreira Gregori \\
\hline & & & Eva Guedes Pérez \\
\hline
\end{tabular}


Meneguel, C. R. A., \& Mateos, M. R. (2021, set./dez.). Perspectivas actuales del turismo gastronómico según las aportaciones del congreso internacional científico-profesional de turismo cultural (Córdoba, España)

(Continua)

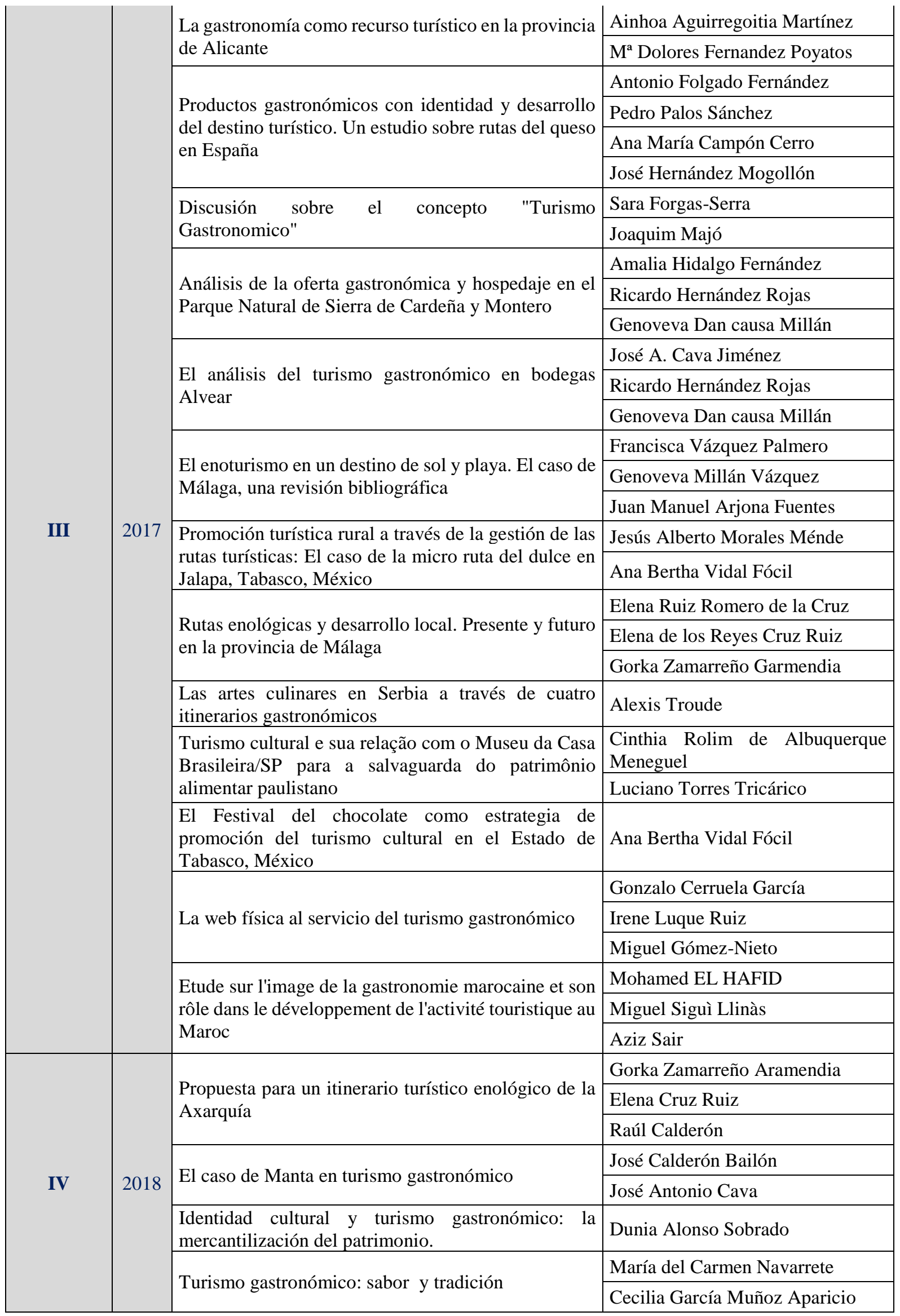


Meneguel, C. R. A., \& Mateos, M. R. (2021, set./dez.). Perspectivas actuales del turismo gastronómico según las aportaciones del congreso internacional científico-profesional de turismo cultural (Córdoba, España)

(Continua)

\begin{tabular}{|c|c|c|c|}
\hline & & \multirow{3}{*}{$\begin{array}{l}\text { El papel del turismo, la gastronomía y la enología en } \\
\text { Andalucía sabor fine food exhibition }\end{array}$} & Francisca Vázquez Palmero \\
\hline & & & Genoveva Millán Vázquez \\
\hline & & & Juan Manuel Arjona Fuentes \\
\hline & & \multirow{2}{*}{$\begin{array}{l}\text { El mezcal un recurso natural y cultural con potencial } \\
\text { para el aprovechamiento turístico }\end{array}$} & Leourbino Gómez Cruz \\
\hline & & & Milagros C. Cong Hermida \\
\hline & & \multirow{2}{*}{$\begin{array}{l}\text { The contribution of gastronomy tourism in the } \\
\text { attractiveness of the destination Agadir in Morocco. }\end{array}$} & Sair Aziz \\
\hline & & & Mohamed Zniber \\
\hline & & \multirow{3}{*}{$\begin{array}{l}\text { Análisis sociolaboral de los trabajadores en hostelería } \\
\text { y restauración por tipología de trabajo en Europa }\end{array}$} & Virginia Navajas- Romero \\
\hline & & & Jaime E. Souto Pérez \\
\hline & & & Ángel Rodríguez López \\
\hline & & \multirow{3}{*}{$\begin{array}{l}\text { Práticas alimentares como narrativa da interação } \\
\text { cultural no turismo rural }\end{array}$} & Ana Maria Costa Berber \\
\hline & & & Renata Menasche \\
\hline & & & Susana Gastal \\
\hline \multirow{27}{*}{$\mathbf{V}$} & \multirow{27}{*}{2019} & $\begin{array}{l}\text { La oferta en oleturismo en la D.O.P Baena. Una } \\
\text { visión de su gestión }\end{array}$ & José Antonio Cava Jiménez \\
\hline & & \multirow{2}{*}{$\begin{array}{l}\text { Revalorización y visibilización de la gastronomía } \\
\text { ancestral andina a través del Turismo Cultural, caso } \\
\text { de estudio: La Pachamanca (Olla de tierra) }\end{array}$} & Sonia Lorena Arellano Guerrón \\
\hline & & & Dayané Mabel Arroyo Mera \\
\hline & & \multirow{3}{*}{$\begin{array}{l}\text { Los productos nativos en la comida novoandina: } \\
\text { alternativa para el desarrollo del turismo } \\
\text { gastronómico }\end{array}$} & Manuel Alberto Mori Paredes \\
\hline & & & Arcelia Olga Rojas Salazar \\
\hline & & & Aida Contreras Yalán \\
\hline & & \multirow{2}{*}{$\begin{array}{l}\text { El Aceite como elemento dinamizador del territorio } \\
\text { para un turismo sostenible y responsable. Caso: Les } \\
\text { Garrigues }\end{array}$} & Maria Abril Sellarés \\
\hline & & & Ricard Tello Murillo \\
\hline & & $\begin{array}{l}\text { Ejemplares de gastronomía de la huasteca potosina: } \\
\text { identidad cultural mexicana, San Luis } \\
\text { Potosí, México }\end{array}$ & María Fernanda Chávez Pérez \\
\hline & & \multirow{2}{*}{ Patrimonio gastronómico de Córdoba (España) } & Rafael Moreno Rojas \\
\hline & & & Ricardo Hernandez Rojas \\
\hline & & \multirow{2}{*}{$\begin{array}{l}\text { Turismo gastronómico como aproximación } \\
\text { conceptual al turismo cultural }\end{array}$} & Esteban Arias Castañeda \\
\hline & & & Rubén Pozo Moreano \\
\hline & & $\begin{array}{l}\begin{array}{l}\text { Turismo gastronómico y } \\
\text { cordobés, versión Argentina. }\end{array} \\
\text { patrimonio cultural } \\
\end{array}$ & Silvina Andrea Dalmasso \\
\hline & & \multirow{3}{*}{$\begin{array}{l}\text { Turismo rural en la provincial de Córdoba. el turismo } \\
\text { del vino como una estrategia de desarrollo }\end{array}$} & Inmaculada Crespo \\
\hline & & & María Pablo-Romero \\
\hline & & & Javier Sánchez-Rivas \\
\hline & & \multirow{3}{*}{$\begin{array}{l}\text { Gastronomy as a factor of attractiveness for the } \\
\text { destination Morocco }\end{array}$} & Aziz Sair \\
\hline & & & Mohamed El Hafid \\
\hline & & & Samir Laabi \\
\hline & & \multirow{2}{*}{$\begin{array}{l}\text { "La ruta de l'Oli". Las cooperativas como eje } \\
\text { vertebrador de la ruta y dinamizador del territorio }\end{array}$} & Maria Abril Sellarés \\
\hline & & & Ricard Tello Murillo \\
\hline & & \multirow{3}{*}{$\begin{array}{l}\text { Cocina ancestral potosina como instrumento de } \\
\text { patrimonio y encanto turístico: el caso de Mexquitic } \\
\text { de Carmona, San Luis Potosí, México }\end{array}$} & \begin{tabular}{|lrr}
$\begin{array}{l}\text { Mario Iván } \\
\text { Bautista }\end{array}$ & Michel Álvarez \\
\end{tabular} \\
\hline & & & Swarajam Citlali Acosta Acuña \\
\hline & & & Itzel Abigail Jasso Rangel \\
\hline & & \multirow{2}{*}{$\begin{array}{l}\text { El viaje de los alimentos: prácticas turístico-culturales } \\
\text { en mercados urbanos }\end{array}$} & Francesc Fusté Forné \\
\hline & & & F. Xavier Medina \\
\hline
\end{tabular}


Meneguel, C. R. A., \& Mateos, M. R. (2021, set./dez.). Perspectivas actuales del turismo gastronómico según las aportaciones del congreso internacional científico-profesional de turismo cultural (Córdoba, España)

(Conclusão)

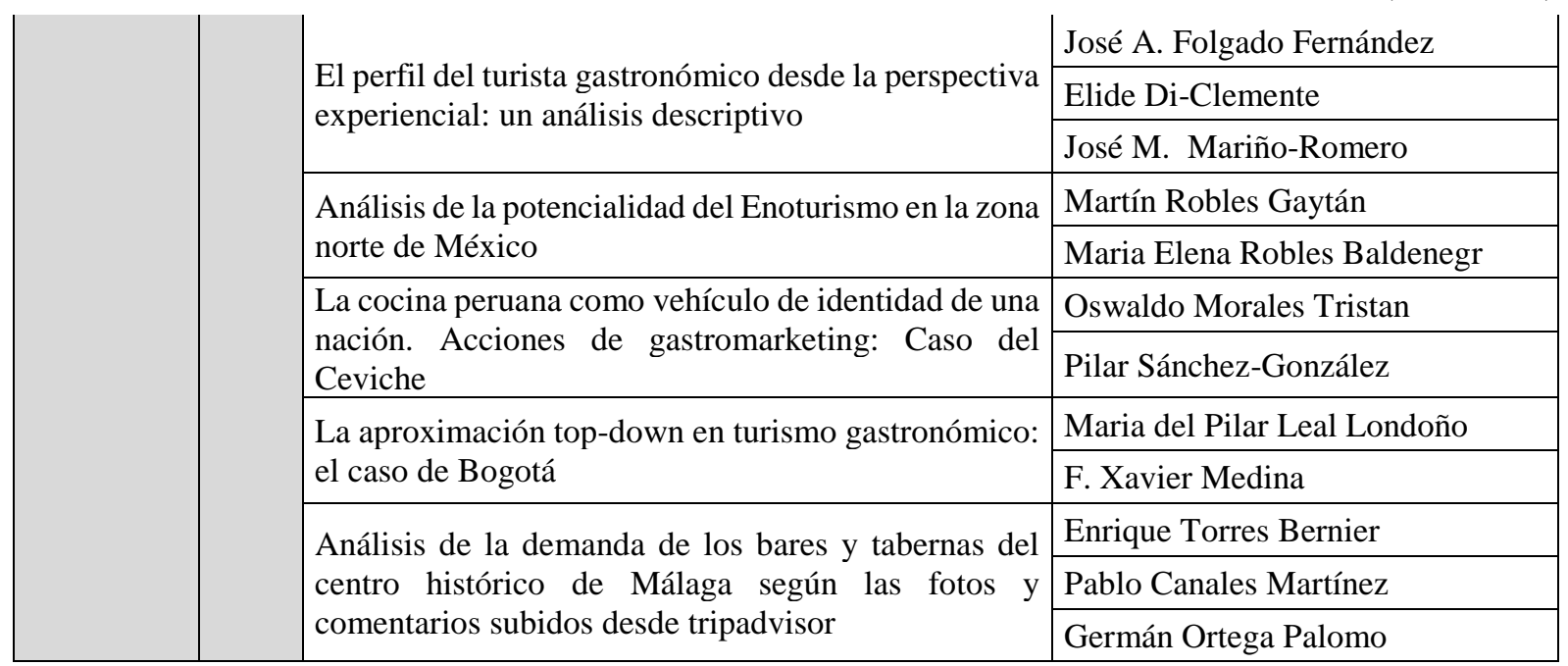

Fuente: Autores (2020).

En el Congreso Internacional Científico-Profesional de Turismo Cultural (2015-2019), el número de trabajos con contenidos centrales sobre turismo gastronómico ha sido ciertamente significativo, ya que ha representado un $9 \%$ del total de las comunicaciones propuestas. La tercera edición del congreso tuvo, además, como tema central la gastronomía, y a lo largo de todo este período se presentaron 13 trabajos, correspondientes a un 9,48\% del total de las comunicaciones defendidas. No obstante, su pico alto se produjo en la última edición de 2019, con un $14,51 \%$ de comunicaciones centradas sobre turismo gastronómico (Tabla 4). Todo ello demuestra la enorme actualidad del debate y la investigación sobre el turismo gastronómico y el despertar de nuevas perspectivas de análisis de esta modalidad turística.

\section{Tabla 4}

Estimativa de comunicaciones sobre turismo gastronómico en el Congreso Internacional Científico-

Profesional de Turismo Cultural (2015-2019)

\begin{tabular}{|c|c|c|c|c|}
\hline EDICIÓN & AÑO & $\begin{array}{c}\text { COMUNICACIONES } \\
\text { PROPUESTAS }\end{array}$ & $\begin{array}{c}\text { COMUNICACIONES DE } \\
\text { TURISMO } \\
\text { GASTRONÓMICO }\end{array}$ & $\begin{array}{l}\text { COMUNICACIONES } \\
\text { DE TURISMO } \\
\text { GASTRONÓMICO - } \\
\text { PORCENTUAL } \\
\end{array}$ \\
\hline I & 2015 & 58 & 7 & $12 \%$ \\
\hline II & 2016 & 91 & 3 & $3 \%$ \\
\hline III & 2017 & 137 & 13 & $9,48 \%$ \\
\hline IV & 2018 & 140 & 9 & $6,42 \%$ \\
\hline V & 2019 & 124 & 18 & $14,51 \%$ \\
\hline \multicolumn{2}{|c|}{ TOTAL } & 550 & 50 & $9 \%$ \\
\hline
\end{tabular}

Fuente: Autores (2020). 
Meneguel, C. R. A., \& Mateos, M. R. (2021, set./dez.). Perspectivas actuales del turismo gastronómico según las aportaciones del congreso internacional científico-profesional de turismo cultural (Córdoba, España)

Se ha identificado un total de 104 autores, mientras que solamente 10 investigaciones han sido realizadas por un solo autor (Tabla 5), contabilizándose un promedio de prácticamente 2 autores por comunicación, de acuerdo con la metodología métrica bibliográfica de Elsevier (2020) y Scopus (2020). Estos datos revelan una destacada colaboración científica a nivel de equipos y grupos de investigación y que, en su mayor parte, integran perfiles académicocientíficos multidisciplinares, siguiendo las tendencias recientes hacia los estudios más integrales e interdisciplinares sobre turismo gastronómico como modalidad turística ciertamente compleja, de contornos difíciles de delimitar y de conceptualización no siempre comúnmente aceptada (Hernández, Rivera, y Millán, 2017).

\section{Tabla 5}

Número de comunicaciones y autores en el Congreso Internacional Científico-Profesional de Turismo Cultural (2015-2019)

\begin{tabular}{|c|c|c|c|}
\hline EDICIÓN & AÑ & NÚMERO DE COMUNICACIONES & NÚMERO DE AUTORES \\
\hline I & 2015 & 7 & 10 \\
\hline II & 2016 & 3 & 8 \\
\hline III & 2017 & 13 & 29 \\
\hline IV & 2018 & 9 & 21 \\
\hline V & 2019 & 18 & 36 \\
\hline \multicolumn{2}{|c|}{ TOTAL } & $\mathbf{5 0}$ & $\mathbf{1 0 4}$ \\
\hline
\end{tabular}

Fuente: Autores (2020).

Igualmente, se ha identificado la participación de varios autores en más de una edición del evento y algunos de ellos han aportado más de un trabajo (Martens, \& Saretzki, 1993), ampliando o profundizando los conocimientos sobre turismo gastronómico y proponiendo nuevas perspectivas de estudio (Lisée, Larivière, \& Archambault, 2008). En concreto, son mayoría los autores que contribuyeron con dos o más comunicaciones (Gráfico 2). 
Meneguel, C. R. A., \& Mateos, M. R. (2021, set./dez.). Perspectivas actuales del turismo gastronómico según las aportaciones del congreso internacional científico-profesional de turismo cultural (Córdoba, España)

\section{Gráfico 2}

Autores con dos o más comunicaciones en el Congreso Internacional Científico-Profesional de Turismo

Cultural (2015-2019)

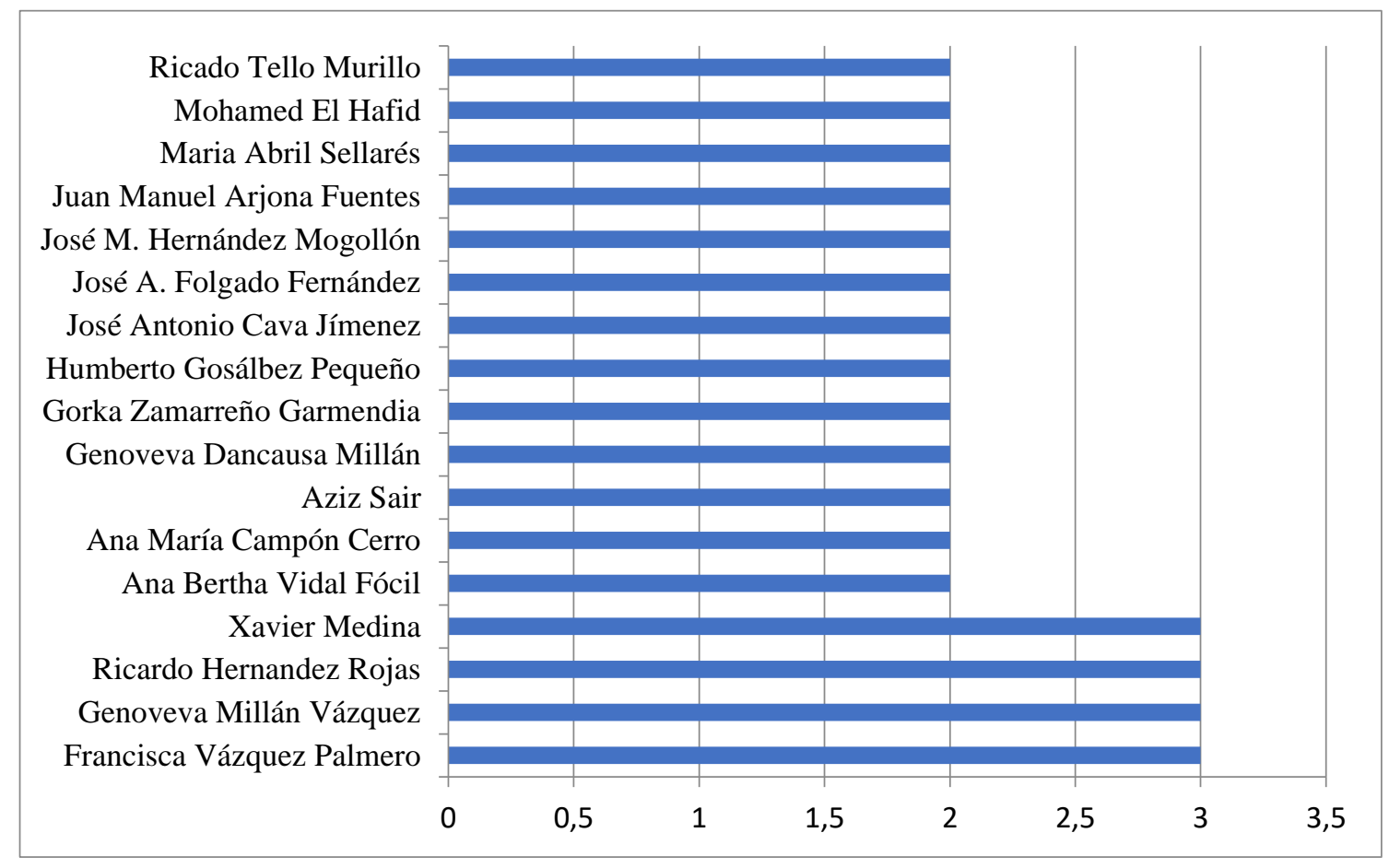

Fuente: Autores (2020).

Del montante final de los trabajos propuestos, se ha observado que en su mayoría las comunicaciones se han presentado escritas en español (88\%), mientras que el resto han sido presentadas en portugués $(6 \%)$, inglés $(4 \%)$ y francés $(1 \%)$.

La mayoría de las comunicaciones propuestas se asignaron a la mesa temática específica de turismo gastronómico, que ha correspondido al 68\% de las investigaciones. Sin embargo, identificamos que el tema del turismo gastronómico tiene un carácter muy transversal, de manera que ha sido abordado desde perspectivas ciertamente diversas, en sus relaciones y sinergias como oferta complementaria en destinos turísticos diversos y en combinación también con productos turísticos también variados (sol y playa, cultural patrimonial, congresos, ruralnaturaleza, etc.). Concretamente un total del $6 \%$ de las comunicaciones fuer incorporado a la mesa temática de turismo cultural y otro $6 \%$ en la mesa de turismo general (Gráfico 3).

De acuerdo con Nechar (2011) resulta primordial analizar la producción académica y científica de cualquier tipología o subsector de actividad turística desde la perspectiva de diferentes áreas de conocimiento para obtener una visión integral. En este sentido, también 
Meneguel, C. R. A., \& Mateos, M. R. (2021, set./dez.). Perspectivas actuales del turismo gastronómico según las aportaciones del congreso internacional científico-profesional de turismo cultural (Córdoba, España)

hemos procedido a identificar las mesas con contenidos relacionados con las Tics y el sector turístico, otras tipologías de turismo complementarias o con incidencia en el turismo cultural y las mesas temáticas sobre economía del turismo. Finalmente, hemos encontrado un total de un 4\% de comunicaciones de ciertos contenidos gastronómicos incluidas en estas mesas específicamente no especializadas en esta temática (Gráfico 3). Y otros trabajos también han sido identificados en otras mesas temáticas como las dedicadas al turismo de festivales y eventos culturales, rutas turísticas y marketing del turismo cultural (un $2 \%$ en cada una de ellas).

\section{Gráfico 3}

Mesas temáticas con propuestas de comunicación sobre turismo gastronómico en el Congreso Internacional Científico-Profesional de Turismo Cultural (2015-2019)

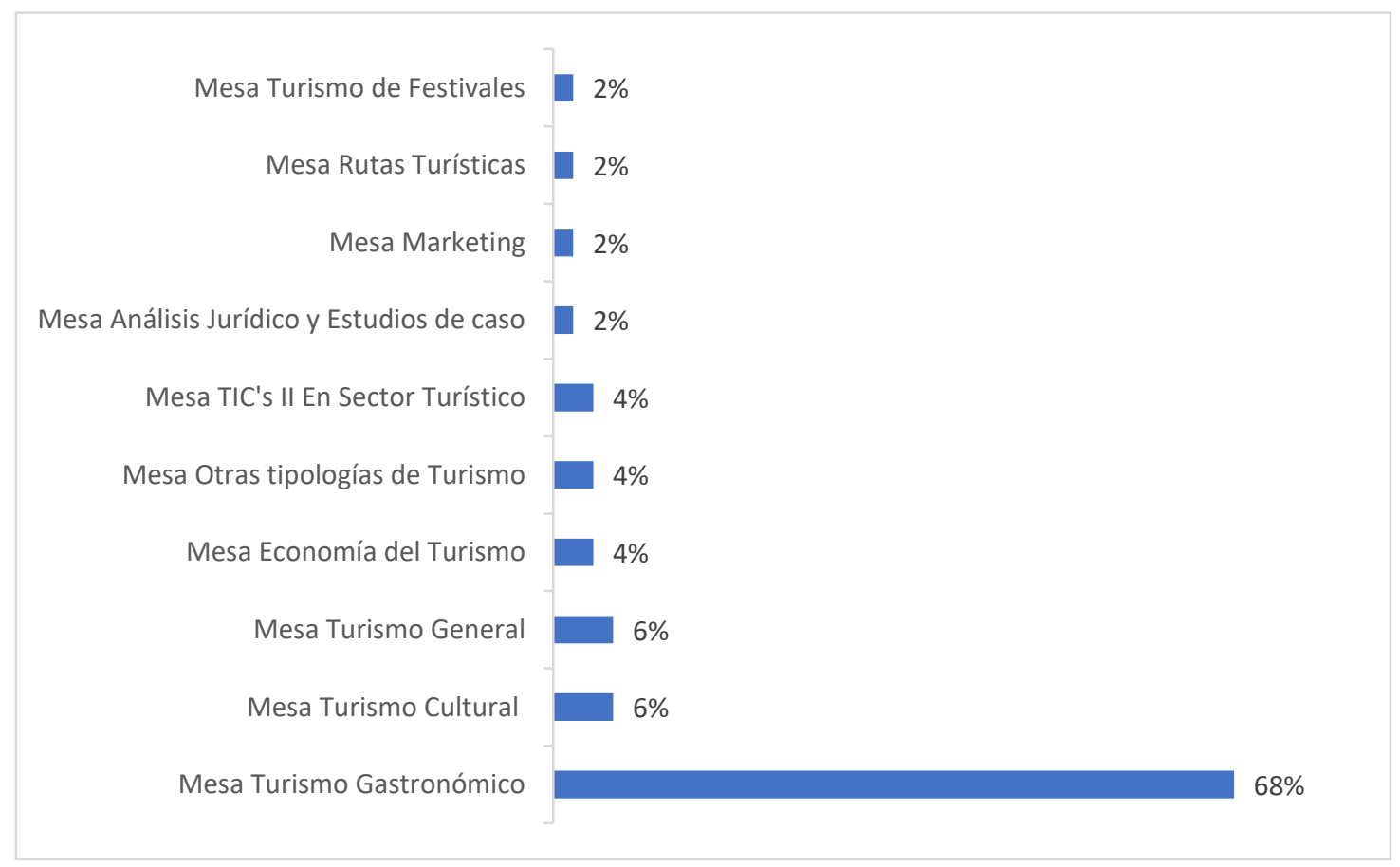

Fuente: Autores (2020).

Igualmente se han identificado trabajos realizados por investigadores pertenecientes a un total de 16 instituciones educativas o científicas diferentes, entre las que son más numerosas las españolas (Universidad de Alicante, Universidad de Córdoba, Universidad de Extremadura, Universidad de Las Palmas de Gran Canaria, Universidad Loyola, Universidad de Sevilla, Universitat Oberta de Catalunya y Escuela Universitaria de Turismo Altamira). Sin embargo, ha ido aumentando significativamente la participación de investigadores de otros numerosos 
Meneguel, C. R. A., \& Mateos, M. R. (2021, set./dez.). Perspectivas actuales del turismo gastronómico según las aportaciones del congreso internacional científico-profesional de turismo cultural (Córdoba, España)

países, encuadrados, por ejemplo, en el Instituto Federal de Educação, Ciência e Tecnologia de São Paulo - IFSP, la Universidade Caxias do Sul, Universidade do Vale do Itajaí y Universidade Federal de Pelotas, todas ellas de Brasil; una institución mexicana (Universidad Juárez Autónoma de Tabasco), una institución portuguesa (Universidade do Algarve) y una última marroquí (The National School of Agadir). Cabe destacar que algunos de los trabajos fueron desarrollados en el marco de una cooperación universitaria interinstitucional, la cual en algunos casos se está viendo desarrollada gracias a los contactos establecidos en este Congreso (Gónzalez-Quijano, 1995; Meadows, 2000; Butler, \& Visser, 2006; Jeong, \& Kim, 2010).

Como dato indicativo de las temáticas abordadas y de la terminología más extendida en el campo científico del turismo gastronómico, hemos de señalar que en las comunicaciones y publicaciones derivadas hemos podido detectar 85 palabras clave utilizadas. Las más frecuentes han sido los términos de "turismo gastronómico" y "turismo" con 5 apariciones cada uno; el término "gastronomía", con 3 apariciones, y los de "comercialización turística", "denominación protegida de origen", "identidad", "promoción", "servicio turístico", "turismo cultural" y "vino", con dos apariciones cada uno. Todas las demás palabras clave aparecieron solo una vez (Figura 1). De hecho, han sido las rutas y productos de enoturismo, oleoturismo y basadas en productos agroalimentarios de calidad o con certificación de Denominación de Origen, las que han centrado el interés de una mayor parte de trabajos.

\section{Figura 1}

Nube de palabras clave de los artículos publicados derivados del Congreso Internacional CientíficoProfesional de Turismo Cultural (2015-2019)

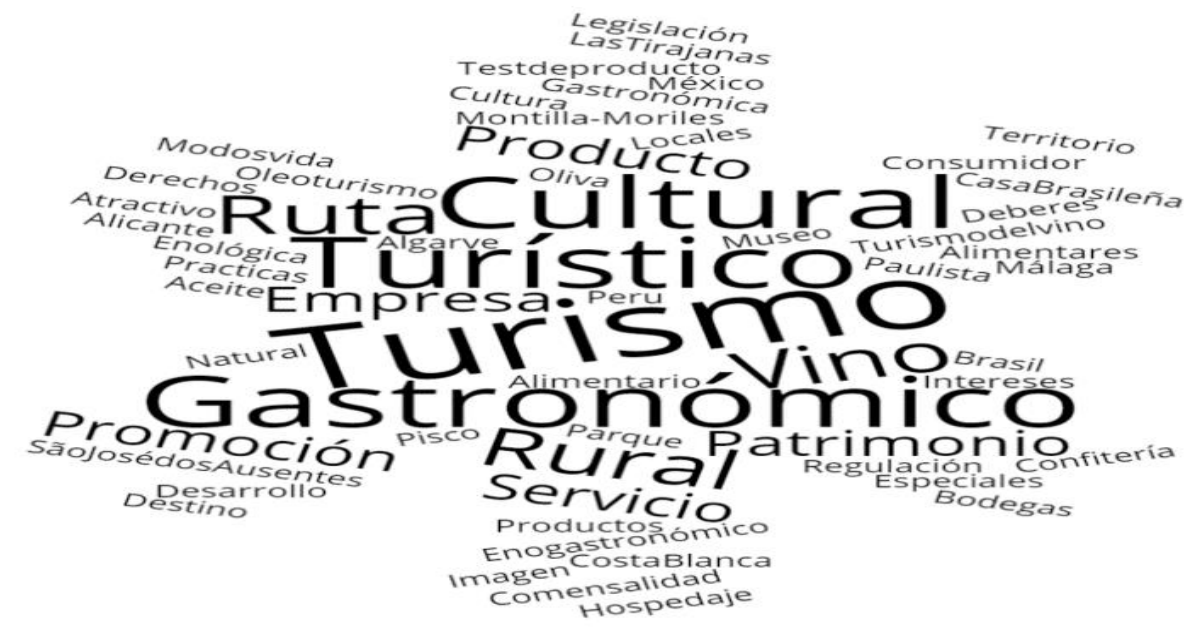

Fuente: Autores (2020). 
Meneguel, C. R. A., \& Mateos, M. R. (2021, set./dez.). Perspectivas actuales del turismo gastronómico según las aportaciones del congreso internacional científico-profesional de turismo cultural (Córdoba, España)

Las discusiones desarrolladas en el Congreso desde diversas ópticas tanto teóricas como prácticas han permitido contribuir ampliamente al conocimiento de las técnicas e instrumentos más eficaces para la puesta en valor del patrimonio gastronómico (Domingos \& Henriques, 2015), su comercialización (Sobrado, 2018), la conservación, difusión y tratamiento de este patrimonio en museos y centros de interpretación (Meneguel \& Tricárico, 2017) y las prácticas alimentarias como instrumentos de interacción y diversidad cultural (Beber, Gastal, \& Menasche, 2018). Asimismo, también hemos podido encontrar estudios y referencias teóricas acerca del patrimonio culinario como herramienta y soporte del turismo gastronómico, de la interpretación de la cultura territorial del entorno geográfico donde se desarrollar y mecanismo de educación y sensibilización patrimonial, en línea con las tendencias de investigación más recientes (Chang, Okumus, Okumus, \& McKercher, 2007; Smith, \& Costello, 2009; Kivela, \& Mak, 2010; Chen, \& Huang, 2017; Choe, \& Kim, 2018; Ellis, Park, Kim, \& Yeoman, 2018).

Las rutas turísticas gastronómicas han tenido también una dedicación importante en las mesas temáticas, considerando como eje central los productos gastronómicos tradicionales y de calidad (Sariego, 2015; Vázquez, Millán, \& Arjona, 2015), las nuevas técnicas de promoción y comercialización de los destinos de turismo cultural (Morales \& Vidal, 2017) y la promoción de esta tipología turística a través de los denominados “festivales gastronómicos" (Vidal, 2017).

Particularmente la modalidad de turismo gastronómico del enoturismo aglutinó una parte importante de los trabajos desde la perspectiva central como producto turístico e instrumento de diversificación de destinos de sol y playa (Vázquez, Millán, \& Arjona, 2015; Moreira \& Guedes, 2016), destinos emergentes de turismo rural y de naturaleza (Medina, 2015), y, en general, de desarrollo local por medio de rutas enológicas (Ruiz, Cruz, \& Zamarreño, 2017). Y, asimismo, y en relación con el enoturismo, se han aportado importantes contribuciones sobre propuestas metodológicas para el diseño de itinerarios turísticos enológicos (Zamarreño, Cruz, \& Calderón, 2018); análisis de motivación y satisfacción de los viajeros asistentes a los festivales enogastronómicos (Muñoz-Fernández, Pérez, \& LópezGuzmán, 2016); aspectos de legislación y ordenación de los servicios y establecimientos de restauración y los derechos de los consumidores (Gonsálbez, 2015; Gonsálbez \& Serrano, 2015) y análisis estructural de la oferta gastronómica (Hidalgo, Hernández, \& Dancausa, 2017). Tales estudios finalmente han generado un intenso debate sobre los recursos turísticos gastronómicos y las distintas temáticas y aspectos emergentes del turismo culinario (Horng, \& Tsai, 2010; Chang, \& Yuan, 2011). 
Meneguel, C. R. A., \& Mateos, M. R. (2021, set./dez.). Perspectivas actuales del turismo gastronómico según las aportaciones del congreso internacional científico-profesional de turismo cultural (Córdoba, España)

Otras temáticas abordadas, por último, han sido aquéllas relacionadas con la consideración de la gastronomía como recurso territorial turístico enriquecedor de la oferta turística de cualquier destino (Aguirregoitia \& Fernandez, 2017), la conformación de productos gastronómicos sostenibles y ecológicos (Folgado-Fernández, Palos-Sánchez, Campón-Cerro, \& Hernández-Mogollón, 2016); el papel de la gastronomía como componente identitario del imaginario de los destinos turísticos (El Hafid \& Aziz, 2017) y el auge y potencialidades del oleoturismo (Hernández, Folgado, \& Campón, 2016). Todos estos contenidos abordados apuntan, como también la literatura especializada más reciente, a la consideración y relevancia del gastronómico como un estímulo, directo o indirecto, a toda la cadena productiva y de valor de la gastronomía (Hwang, Kim, Choe, \& Chung, 2018).

De acuerdo con los resultados de esta investigación, se desprende que la cadena del valor del turismo gastronómico se puede representar como un continuo de variables y elementos multitemáticos o multifacéticos, desde el campo de la producción agroalimentaria hasta el servicio gastronómico y las experiencias excepcionales proporcionadas por los productos del turismo gastronómico en los visitantes. Así, cada elemento es tan importante como el otro para garantizar el desarrollo sostenible de este segmento de demanda turística y generar una experiencia memorable. Por lo tanto, las oportunidades de reflexión, debate, intercambio de experiencias, transferencia de conocimientos y de buenas prácticas proporcionadas por el Congreso Internacional Científico-Profesional de Turismo Cultural fortalecen los niveles de implicación y cooperación científico-técnica, evidenciando a relevancia de los congresos y eventos como difusores de estudios sobre el turismo gastronómico.

\section{Conclusiones}

El análisis realizado demuestra el importante crecimiento y la misma actualidad de las contribuciones científicas centradas en el turismo gastronómico y sus diversas submodalidades y manifestaciones, tanto en España como en el extranjero, y no sólo en el ámbito académicocientífico sino también en el técnico-profesional y en el de las Administraciones Públicas con competencias en turismo y desarrollo local.

Los artículos publicados y presentados en este Congreso han servido para contar con un marco teórico y metodológico mucho más maduro y estructurado sobre la materia, además de para aclarar algunas confusiones terminológicas y conceptuales. El análisis de esta temática congresual, como ha ocurrido con otras similares, nos ha permitido también conocer el 
Meneguel, C. R. A., \& Mateos, M. R. (2021, set./dez.). Perspectivas actuales del turismo gastronómico según las aportaciones del congreso internacional científico-profesional de turismo cultural (Córdoba, España)

comportamiento y los enfoques de análisis de los investigadores a la hora de consolidar conocimiento científico sobre la materia.

A pesar de las dificultades impuestas por la pandemia provocada por la pandemia del COVID-19, este Congreso Internacional Científico-Profesional de Turismo Cultural realizó su VII edición en 2021, con carácter online, generando nuevos debates, reflexiones críticas y intercambios de experiencias y conocimiento entre el mundo académico y el profesional. Además en esta última edición ha aportado un aspecto innovador, al grabar y difundir en redes sociales todas las sesiones temáticas y para ponerse a disposición del público interesado a través del portal web del vento para su acceso en cualquier momento.

La diversidad de perspectivas, contenidos y herramientas metodológicas sobre el turismo gastronómico nos indican no sólo que estamos ante un fenómeno ciertamente complejo y nada fácil de abordar, sino también de importantes potencialidades para la mejora de la oferta y atractivos de cualquier destino turístico, ya sea como motivación principal de la demanda, con efectos más cualitativos que cuantitativos, o como oferta secundaria y complementaria de otras principales, que es como se manifiesta en la mayoría de los estudios de caso abordados. Todo esto explica el tratamiento de cuestiones y temas tan diversos como el análisis de perfil de la demanda, los estudios sobre la oferta, las implicaciones socio laborales, la valorización del patrimonio agroalimentario, el papel identitario y de afianzamiento como marca cultural y turística de muchos destinos que tiene esta tipología turística, así como impulso de sus tradiciones, formas de vida y costumbres, el marketing gastronómico, la incidencia de los productos gastronómicos en el desarrollo de la economía social y los mercados urbanos o el diseño y estructuración de rutas turísticas especializadas en gastronomía.

Hasta ahora no se había realizado ningún estudio con esta perspectiva en particular a través de una fuente congresual, por lo que esta investigación ha contribuido finalmente a ampliar los horizontes y puntos de mira del turismo gastronómico en el ámbito académicocientífico, teórico-conceptual y en el técnico-profesional o práctico, mostrando las tendencias más recientes e innovadoras y los productos turístico-gastronómicos más emergentes y de mayores potencialidades de desarrollo futuro. Y desde nuestro punto de vista, y tras analizar los resultados, entendemos que los futuros investigadores que planean realizar una investigación basada en los anales y actas de los congresos y eventos especializados pueden tener este estudio como una guía de referencia útil y recurrente.

Sin perjuicio de estas consideraciones, somos conscientes, eso sí, de que el análisis exploratorio realizado en este estudio presenta no pocas limitaciones en sus resultados finales, 
Meneguel, C. R. A., \& Mateos, M. R. (2021, set./dez.). Perspectivas actuales del turismo gastronómico según las aportaciones del congreso internacional científico-profesional de turismo cultural (Córdoba, España)

siendo necesario la apertura de nuevas investigaciones bibliográficas que permitan ir conformando un marco teórico, metodológico y conceptual sólido para afrontar con mayor rigor la tipología del turismo gastronómico. El reconocimiento de esta limitación genera, en cualquier caso, una oportunidad de mejorar la investigación, la transferencia de conocimiento y la comprensión de esta temática turística.

\section{Agradecimiento}

Fundación Carolina por promover el intercambio de docentes y de investigación a través del Programa de movilidad de profesores entre Universidades de Brasil y España.

\section{Referencias}

Aguirregoitia, A., \& Fernandez, Z. (2017). La gastronomía como recurso turístico en la provincia de Alicante. International Journal of Scientific Management and Tourism, 3(3), 25-48.

Appadurai, A. (2001) La modernidade desbordada. Dimensiones culturales de la globalización. México: Trilce-FCE.

Beber, A. M. C., Gastal, S., \& Menasche, R. (2018). Práticas alimentares como narrativa da interação cultural no turismo rural. International Journal of Scientific Management and Tourism, 4(2), 181-196.

Benhamou, F. (2016). Economia do patrimônio cultural. São Paulo: Edições Sesc São Paulo.

Bernard, H. R. (1994). Research methods in anthropology: Qualitative and quantitative approaches ( $2^{\text {nd }}$ ed.). Thousand Oaks, CA: Sage.

Butler, L., \& Visser, M. S. (2006). Extending citation analysis to non-source items. Scientometrics, 66(2), 327-343. https://doi.org/10.1007/s11192-006-0024-1

Chang, R. C. Y., Kivela, J., \& Mak, A. H. N. (2010). Food preferences of Chinese tourists. Annals of Tourism Research, 37(4), 989-1011. https://doi.org/10.1016/j.annals.2010.03.007

Chang, W., \& Yuan, J. (2011). A taste of tourism: Visitors' motivations to attend a food Festival. Event Management, 15(1), 13-23. https://doi.org/10.3727/152599511X12990855575024

Chen, Q., \& Huang, R. (2017). Local food in China: a viable destination attraction. British Food Journal, 120(1), 146-157. https://doi.org/10.1108/BFJ-03-2017-0135 
Meneguel, C. R. A., \& Mateos, M. R. (2021, set./dez.). Perspectivas actuales del turismo gastronómico según las aportaciones del congreso internacional científico-profesional de turismo cultural (Córdoba, España)

Choe, J., \& Kim, S. (2018). Effects of tourists' local food consumption value on attitude, food destination image, and behavioral intention. International Journal of Hospitality Management, 71, 1-10. https://doi.org/10.1016/j.ijhm.2017.11.007

Congreso Internacional Científico-Profesional de Turismo Cultural. (2020). Portal web oficial. Retrieved from: http: Ilwww.congresointernacionalturismocultural.com. Access: 12 jan. 2020.

Domingos, S., \& Henriques, C. (2015). Património Gastronómico e sua valorização pelas entidades público-privadas. O caso da Doçaria da região do Algarve. International Journal of Scientific Management and Tourism, 1(3), 213-231.

Donaire, J. A. (2012). Turismo cultural. Entre la experiencia y el ritual. Bellcaire d'Empordà: Edicions Vitel.a.

El Hafid, M., \& Aziz, S. (2017). Etude sur l'image de la gastronomie marocaine et son rôle dans le développement de l'activité touristique au Maroc. International Journal of Scientific Management and Tourism, 3(4), 381-395.

Ellis, A., Park, E., Kim, S., \& Yeoman, I. (2018). What is food tourism?. Tourism Management, 68(October), 250-263. https://doi.org/10.1016/j.tourman.2018.03.025

Everett, S. (2012). Production places or consumption spaces? The place-making agency of food tourism in Ireland and Scotland. Tourism Geographies, 14(4), 535-554. https://doi.org/10.1016/j.tourman.2018.03.025

Fernández, A. H., Rojas, R. D. H., \& Millán, G. D. (2017). Análisis de la oferta gastronómica y hospedaje en el Parque Natural de Sierra de Cardeña y Montoro. International Journal of Scientific Management and Tourism, 3(2), 29-43.

Fócil, A. B. V. (2017). El Festival del chocolate como estrategia de promoción del turismo cultural en el Estado de Tabasco, México. International Journal of Scientific Management and Tourism, 3(2), 501-512.

Folgado-Fernández, J. A., Palos-Sánchez, P. R., Campón-Cerro, A. M. \& HernándezMogollón, J. M. (2017). Productos gastronómicos con identidad y desarrollo del destino turístico. Un estudio sobre rutas del queso en España. International Journal of Scientific Management and Tourism, 3(2), 501-512.

Gonsálbez, H. Y. (2015). ¿Merecen ser turísticos todas las empresas y establecimientos de restauración en Andalucía? A propósito del concepto de servicio turístico de restauración y clases de establecimientos en la legislación turística de Andalucía. International Journal of Scientific Management and Tourism, 1(1), 135-151.

Gonsálbez, H. Y., \& Serrano, J. (2015). Derechos de usuarios y deberes de las empresas de restauración a la luz de la legislación turística y de defensa del consumidor en Andalucía. International Journal of Scientific Management and Tourism, 1(3), 73-94. 
Meneguel, C. R. A., \& Mateos, M. R. (2021, set./dez.). Perspectivas actuales del turismo gastronómico según las aportaciones del congreso internacional científico-profesional de turismo cultural (Córdoba, España)

Gónzalez-Quijano, C. (1995). El Mercado de reuniones, congresos e incentivos en España. Estudios Turísticos, 126, 179-190.

Hall, C. M., \& Sharples, L. (2003). The consumption of experiences or the experience of consumption? An introduction to the tourism of taste. In Hall, C. M., Sharples, L., Mitchell, R., Macionis, N., \& Cambourne, B. (Eds.), Food tourism around the world (pp. 1-24). London: Routledge.

Hall, C. M., \& Sharples, L. (2008). Food and wine festivals and events around the world. Oxford: Butterworth-Heinemann.

Hauser, J., Tellis, G. J., \& Griffin, A. (2006). Research on innovation: A review and agenda for marketing science. Marketing Science, 25(6), 687-717. https://doi.org/10.1287/mksc.1050.0144

Henderson, J. C. (2009). Food tourism reviewed. British Food Journal, 111(4), 317-326. https://doi.org/10.1108/00070700910951470

Hernández, J. M., Folgado-Fernández, J. A., \& Campón, A. M. (2016). Oleoturismo en la sierra de gata y las Hurdes (Cáceres): análisis de su potencial a través de un test de producto. International Journal of Scientific Management and Tourism, 2(1), 333-354.

Hernández, R., Rivera, M., \& Millán, M.G. (2017). La integración de los productos agroalimentarios de las tiendas "gourmet" en la oferta turística gastronómica de la ciudad de Córdoba. Investigaciones Turísticas, 13, 178-203.

https://doi.org/10.14198/INTURI2017.13.09

Hidalgo, A., Hernández, R. D., \& Dancausa, G. (2017), Análisis de la oferta gastronómica y hospedaje en el Parque Natural de Sierra Cardeña y Montoro. International Journal of Scientific Management and Tourism, 3(2), 29-43.

Horng, J. S., \& Tsai, C. T. (2010). Government websites for promoting East Asian culinary tourism: A cross-national analysis. Tourism Management, 31(1), 74-85. https://doi.org/10.1016/j.tourman.2009.01.009

Hwang, J., Kim, S., Choe, J., \& Chung, J. (2018). Exploration of the successful glocalization of ethnic food: A case of Korean food. International Journal of Contemporary Hospitality Management, 30(12), 3656-3367. https://doi.org/10.1108/IJCHM-072017-0452

Jeong, S., \& Kim, H. G. (2010). Intellectual structure of biomedical informatics reflected in scholarly events. Scientometrics, 85(2), 541-551. https://doi.org/10.1007/s11192-0100166-z

Kivela, J., \& Crotts, J. (2006). Tourism and gastronomy: gastronomy's influence on how tourists experience a destination. Journal of Hospitality \& Tourism Research (3): 354377. https://doi.org/10.1177/1096348006286797 
Meneguel, C. R. A., \& Mateos, M. R. (2021, set./dez.). Perspectivas actuales del turismo gastronómico según las aportaciones del congreso internacional científico-profesional de turismo cultural (Córdoba, España)

Lisée, C., Larivière, V., \& Archambault, É. (2008). Conference proceedings as a source of scientific information: a bibliometric analysis. Journal of the American Society for Information Science and Technology, 56(11), 1776-1784. https://doi.org/10.1002/asi.20888

Martens, B., \& Saretzki, T. (1993). Conferences and courses of biotechnology: describing scientific communication by exploratory methods. Scientometrics, 27(3), 237-260. https://doi.org/10.1007/BF02016941

Martins, G. de A., \& Theóphilo, C. R. (2009). Metodologia da investigação científica para ciências sociais aplicadas, 2a . São Paulo: Atlas, 2009.

Meadows, A. J. A comunicação científica. Brasília: Briquet de Lemos Livros, 2000.

Medina, X. (2015). Tourism and culture in names food and wine origin: The case of the Region Tokaj (Hungary). International Journal of Scientific Management and Tourism, 3(1), 167-177.

Meneguel, C. R. A., \& Tricárico, L. T. (2017). Turismo cultural e sua relação com o Museu da Casa Brasileira-SP para a salvaguarda do patrimônio alimentar paulistano. International Journal of Scientific Management and Tourism, 3(1), 491-511.

Morales, J., \& Vidal, A. (2017). Promoción turística rural a través de la gestión de las rutas turísticas: El caso de la micro ruta del dulce en Jalapa, Tabasco, México. International Journal of Scientific Management and Tourism, 3(3), 373-380.

Moreira, P., \& Guedes, E. (2016). Enoturismo en un destino del sol y playa. El caso de la bodega Las Tirajanas en Gran Canaria - España. International Journal of Scientific Management Tourism, 2(3), 205-224.

Muñoz-Fernández, G., Pérez, J. \& López-Guzmán. (2016). Las sinergias entre el vino, los viajes y los festivales enogastronómicos. Un análisis de motivación y satisfacción. International Journal of Scientific Managment Tourism, 2(3), 225- 240.

Nechar, C. M. (2011). Epistemologia crítica do turismo: que é isso?. Revista Turismo em Análise, 22(3), 516-538). https://doi.org/10.11606/issn.1984-4867.v22i3p516-538

Okumus, B., Okumus, F., \& McKercher, B. (2007). Incorporating local and international cuisines in the marketing of tourism destinations: The cases of Hong Kong and Turkey. Tourism Management, 28(1), 253-261.

https://doi.org/10.1016/j.tourman.2005.12.020

Richards, G. (2002). Gastronomy: an essential ingredient in tourism production and consumption?. In: HJALAGER, A.-M., \& Richards, G. (Org). Tourism and gastronomy (pp.3-20). London: Routledge.

Richards, G. (2007). Cultural tourism. Global and local perspectives. London y Oxford: Haworth. 
Meneguel, C. R. A., \& Mateos, M. R. (2021, set./dez.). Perspectivas actuales del turismo gastronómico según las aportaciones del congreso internacional científico-profesional de turismo cultural (Córdoba, España)

Rojek, C., \& Urry, J. (1997). Touring cultures. Transformation of travel and theory. London: Routledge.

Ruiz, E., Cruz, E. R., \& Zamarreño, G. (2017). Rutas enológicas y desarrollo local. Presente y futuro en la provincia de Málaga. International Journal of Scientific Management and Tourism, 3(1), 283-310.

Russo, A. P., \& Richards, G. (2016). Reinventing the local in tourism: Producing, consuming and negotiating place. Bristol: Channel View Publications.

Sariego, I. (2015). Las rutas del pisco como elementos turísticos representativos de la cultura peruana. International Journal of Scientific Management and Tourism, 1(1), 167-196.

Selby, M. (2004). Understanding urban tourism. Image, culture \& experience. London and New York: Tauris.

Silverman, D. (2005). Doing qualitative research: A practical handbook. London: Sage.

Smith, S., \& Costello, C. (2009). Culinary tourism: Satisfaction with a culinary event utilizing importance-performance grid analysis". Journal of Vacation Marketing, 15(2), 99 110. https://doi.org/10.1177/1356766708100818

Sobrado, D. A. (2018). Identidad cultural y turismo gastronómico: la mercantilización del patrimonio. International Journal of Scientific Management and Tourism, 4(2), 51-71.

Vázquez, F., Millán, G., \& Arjona, J. M. (2015). Enoturismo en un destino de sol y playa. El caso de Málaga, uma revisión bibliográfica. International Journal of Scientific Management and Tourism, 3(4), 591-608.

Vidal, A. B. (2017). El Festival del chocolate como estrategia de promoción del turismo cultural en el Estado de Tabasco, México. International Journal of Scientific Management and Tourism, 3(2), 501-512.

Yoo, J. J-E., \& Weber, K. (2005). Progress in convention tourism research. Journal of Hospitality \& Tourism Research, 29(2), 194-222. https://doi.org/10.1177/1096348004272177

Zamarreño, G., Cruz, E., \& Calderón, R. (2018). Propuesta metodológica para un itinerario turístico enológico de la Axarquía en Málaga. International Journal of Scientific Management and Tourism, 4(2), 571-588. 